\title{
Active dispersal of Aedes albopictus: a mark-release-recapture study using self-marking units
}

Laura Vavassori ${ }^{1,2^{*}}$, Adam Saddler ${ }^{1,2,3}$ and Pie Müller ${ }^{1,2}$

\begin{abstract}
Background: Understanding the dispersal dynamics of invasive mosquito species is fundamental to improve vector surveillance and to target control efforts. Aedes albopictus has been deemed a poor flyer as its range of active dispersal is generally assumed to be limited to a few hundred metres, while laboratory studies suggest this mosquito could actually fly several kilometres. The discrepancy may be due to differences in the local environment or to the methodological approach. In Switzerland, Ae. albopictus has been present since 2003 and has since then expanded its range. While passive dispersal is a key driver, it remains unclear how far this mosquito spreads through active flight and what the age structure and size of the local population are, all important parameters for vector surveillance and control.

Method: We investigated the active dispersal, daily survival rate and population size of Ae. albopictus in mark-releaserecapture studies in Coldrerio and Lugano, two areas of intensive control in Switzerland. To mark mosquitoes emerging from breeding sites, we used self-marking units with fluorescent pigment that have minimal impact on mosquito survival and behaviour. We recaptured the adult mosquitoes with BG-Sentinel traps within a radius of $1 \mathrm{~km}$ from the marking units over 22 consecutive days.
\end{abstract}

Results: We found that $77.5 \%$ of the recaptured Ae. albopictus individuals flew further than $250 \mathrm{~m}$, the limit that is usually deemed sufficient for vector containment. The average age of females and males was 8.6 days and 7.8 days in Coldrerio and Lugano, respectively, while the estimated mosquito population densities were 134 mosquitoes/ha in Coldrerio and 767 mosquitoes/ha in Lugano.

Conclusions: Self-marking units are an effective tool to mark wild mosquitoes. Using this approach, we found that mosquitoes survive long enough to potentially transmit arboviral disease in our study area and that host-seeking Ae. albopictus females may travel further than previously assumed for European mosquito populations. This finding has direct implications for vector control as emergency treatments around positive cases, as well as surveillance and control around detections of new infestations, might need to be extended beyond the usual recommended range of just a few hundred metres.

Keywords: Population dynamics, Invasive mosquitoes, Flight range, Mosquito survival

\section{Background}

The Asian tiger mosquito, Aedes albopictus (Skuse, 1894) is listed as one of the most invasive mosquito species worldwide [1]. Besides the considerable biting nuisance,

\footnotetext{
*Correspondence: lauravavassori4@gmail.com

1 Swiss Tropical and Public Health Institute, Socinstrasse 57, P.O. Box, 4002 Basel, Switzerland

Full list of author information is available at the end of the article
}

Ae. albopictus is a vector of several pathogens, including chikungunya, dengue and Zika virus, as well as dirofilarial worms [2, 3]. With its global spread and an increasing number of infected travellers returning from diseaseendemic countries, outbreaks of tropical and subtropical mosquito-borne diseases have become a reality also in Europe, exemplified by the autochthonous cases of chikungunya in Italy $[4,5]$ and France, and dengue in 
Croatia, France and Spain [6-11] with Ae. albopictus identified as the incriminated vector.

Due to desiccation resistant eggs, Ae. albopictus is passively spread across the globe through the international trade of used tyres and other artificial containers. At a more regional scale, adults are travelling as blind passengers in vehicles and are dispersed particularly along the main traffic routes [12-14]. In contrast, Ae. albopictus has been deemed a poor flyer as its range of active dispersal is generally assumed to be limited to a few hundred metres (Table 1), while laboratory studies suggest the mosquito could actually fly several kilometres [15], leaving some uncertainties as to whether its actual flight range might have been underestimated.

Understanding the dispersal dynamics of invasive mosquito species is fundamental to improve vector surveillance and to target control efforts. Whether being used to control a new or existing mosquito infestation, the dispersal potential of a mosquito species will have important implications for the spatial scale at which control interventions need to be deployed. For example, if a returning traveller presents viremia in an area where the local mosquito population is competent to transmit the virus, control measures may be deployed within the vector's flight range in order to minimise the risk of further spread. Current guidelines recommend vector control measures to be implemented within a radius of $100 \mathrm{~m}$ from the residence of a suspected or confirmed case or $300 \mathrm{~m}$ of a cluster of cases [16-19].

Active dispersal, population size and other mosquito population related parameters have frequently been investigated in mark-release-recapture (MRR) studies, where adult mosquitoes are coloured with fluorescent pigment, released and then recaptured in traps [20,21]. In most studies with Ae. albopictus, the mosquitoes were sourced from laboratory colonies that had been reared over many generations (Table 1). However, rearing conditions have a strong influence on mosquito physiology, which will also influence dispersal behaviour [22]. Additionally, mosquitoes have mostly been individually marked with tedious and time-consuming methods, involving direct manipulation of mosquitoes, casting doubt on the validity of such MRR studies.

In Switzerland Ae. albopictus was first detected in 2003 at a motorway service area [23] and since then has continued to spread across larger areas of the Canton of Ticino [13]. Despite an intensive control programme based on public awareness campaigns, larval source reduction and larviciding, the mosquito has spread across many areas in Ticino. Nevertheless, relative population densities have been shown to be twice as high in non-intervention areas in neighbouring regions in Italy, supporting the hypothesis that the vector control efforts still have a major impact on mosquito density [24].
In this study we aimed at estimating the dispersal patterns of Ae. albopictus in an area where control measures are in place, while overcoming the drawbacks of commonly used methods to mark released mosquitoes. Our results provide the first data on active dispersal in Switzerland and we discuss them in the framework of risk assessment of disease transmission and effective vector control.

\section{Methods}

\section{Study sites}

We conducted our MRR experiments at two sites in southern Switzerland in the Canton of Ticino, Coldrerio and Lugano (Fig. 1) from 9th to 31st of August and from 8th to 28th of September 2018, respectively. These dates coincide with the peak of the Ae. albopictus season in Ticino [25].

Coldrerio $\left(45^{\circ} 51^{\prime \prime} \mathrm{N}, 8^{\circ} 59^{\prime \prime} \mathrm{E}, 351 \mathrm{~m}\right)$ is a municipality in the district of Mendrisio and in 2017 had a population of 2892 inhabitants [26]. Coldrerio covers an area of 246 ha of which $20 \%$ ( 47 ha) are woods, $50 \%$ (124 ha) are agricultural areas and 30\% (74 ha) are urban. The landscape is representative for a municipality of southern Switzerland, where the land is primarily used for agricultural purposes (i.e. mainly vineyards). The highway E35, connecting Rome with Amsterdam, crosses the municipality of Coldrerio where the first specimens of Ae. albopictus in Switzerland were found in an ovitrap placed at the motorway service station in 2003 [23].

Lugano $\left(46^{\circ} 00^{\prime \prime} \mathrm{N}, 8^{\circ} 57^{\prime \prime} \mathrm{E}, 273 \mathrm{~m}\right)$ is the largest city in the canton and had a population of 63,932 in 2017 [26]. Lugano city centre lies on Lake Lugano and is surrounded by two mountains, Monte Brè $(925 \mathrm{~m})$ and San Salvatore $(912 \mathrm{~m})$ that overlook the lake. Lugano covers a surface of 30,811 ha, of which $66 \%(20,288 \mathrm{ha})$ are covered by forests, $12 \%$ (3654 ha) are agricultural areas, 17\% (5126 ha) are urban land and $5 \%$ (1730 ha) are covered by water.

\section{Self-marking units}

We investigated the active dispersal behaviour of $A e$. albopictus using a unit in which mosquitoes emerging from a breeding site mark themselves with fluorescent pigment (Fig. 2). The unit was originally developed for Culex mosquitoes [27] and has also already been deployed in a study to mark emerging Ae. albopictus [28] in the field.

In the present study, the self-marking units consisted of three parts: an aluminium structure, a removable exit grid and cheese cloth strips of $55 \times 20 \mathrm{~cm}$ that are impregnated with fluorescent pigment (Fig. 2). The aluminium structure supports the removable exit grid that is made of a wooden frame and aluminium rods while the colour-pigmented cheese cloth strips are suspended and 


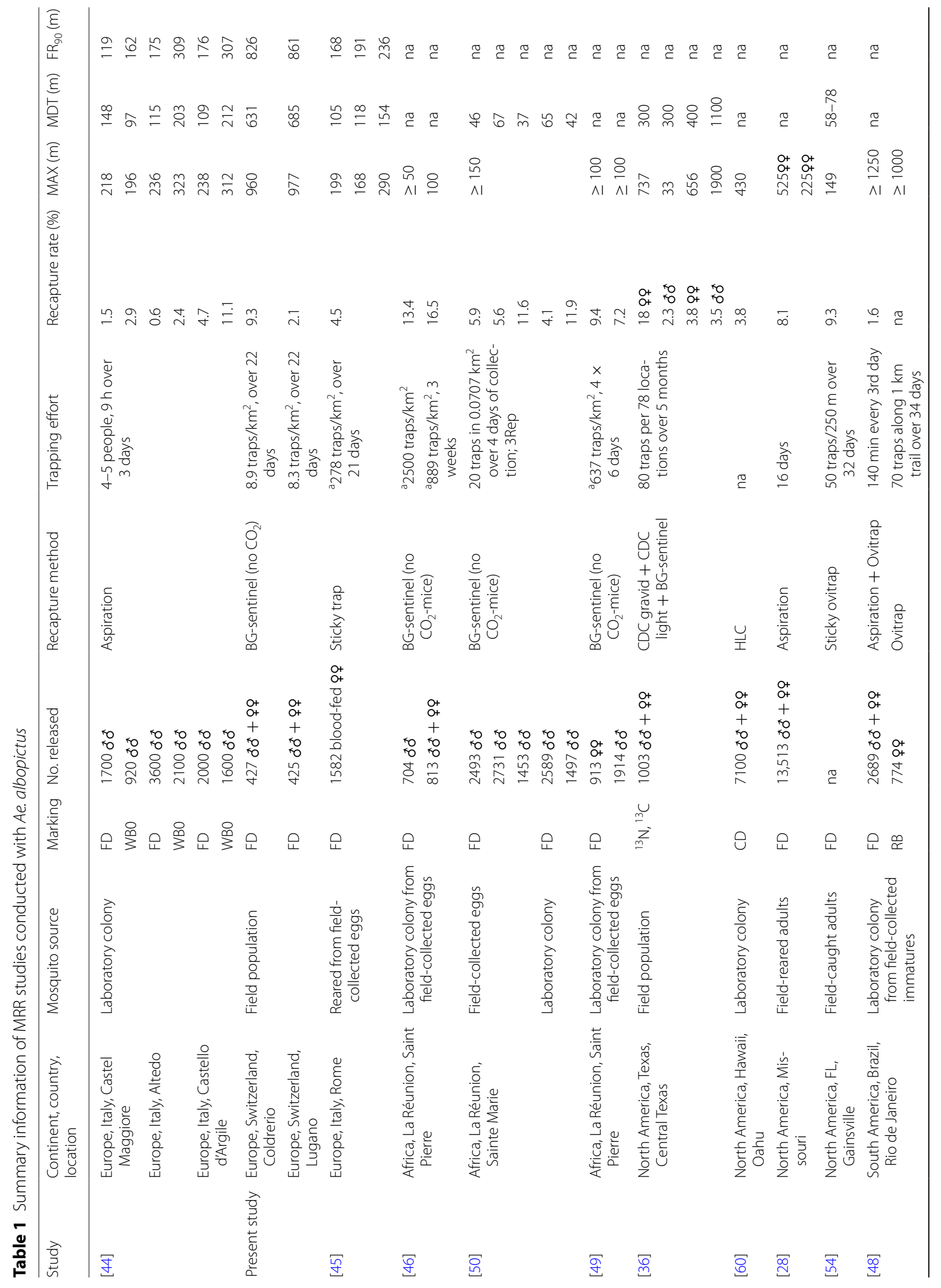




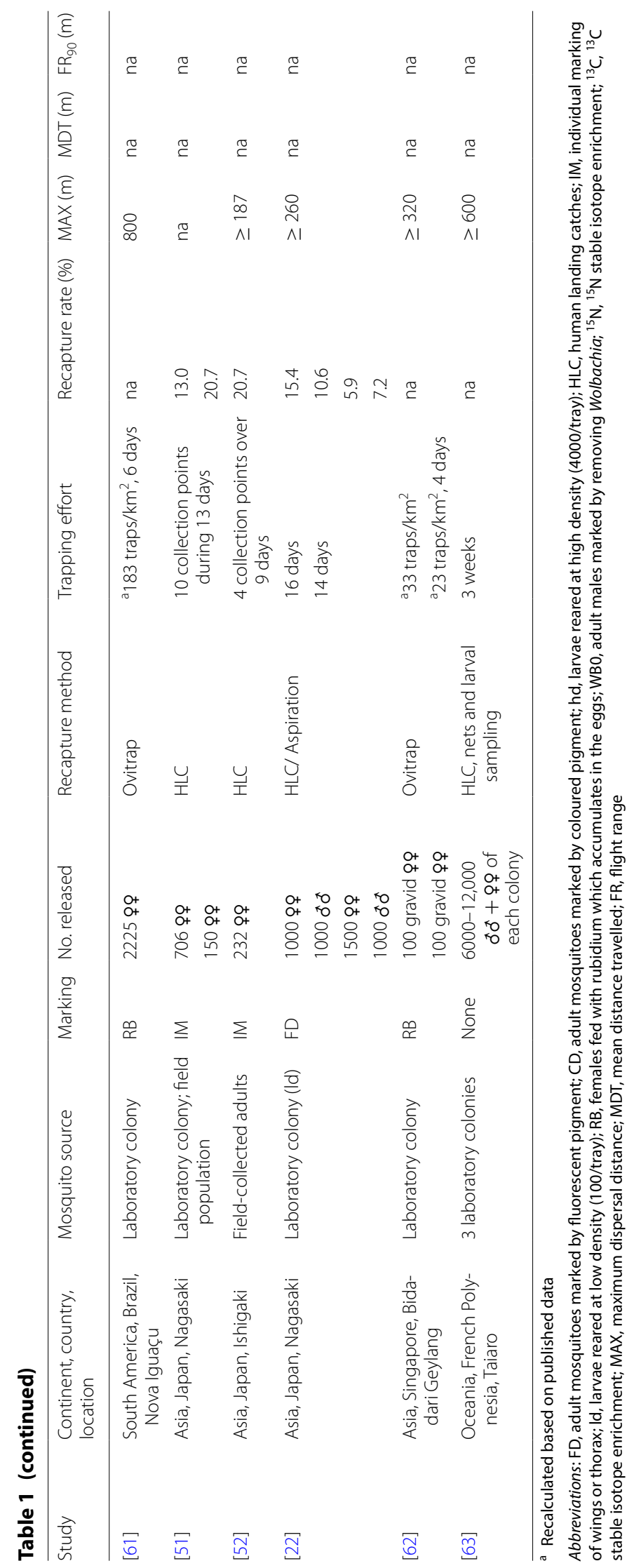




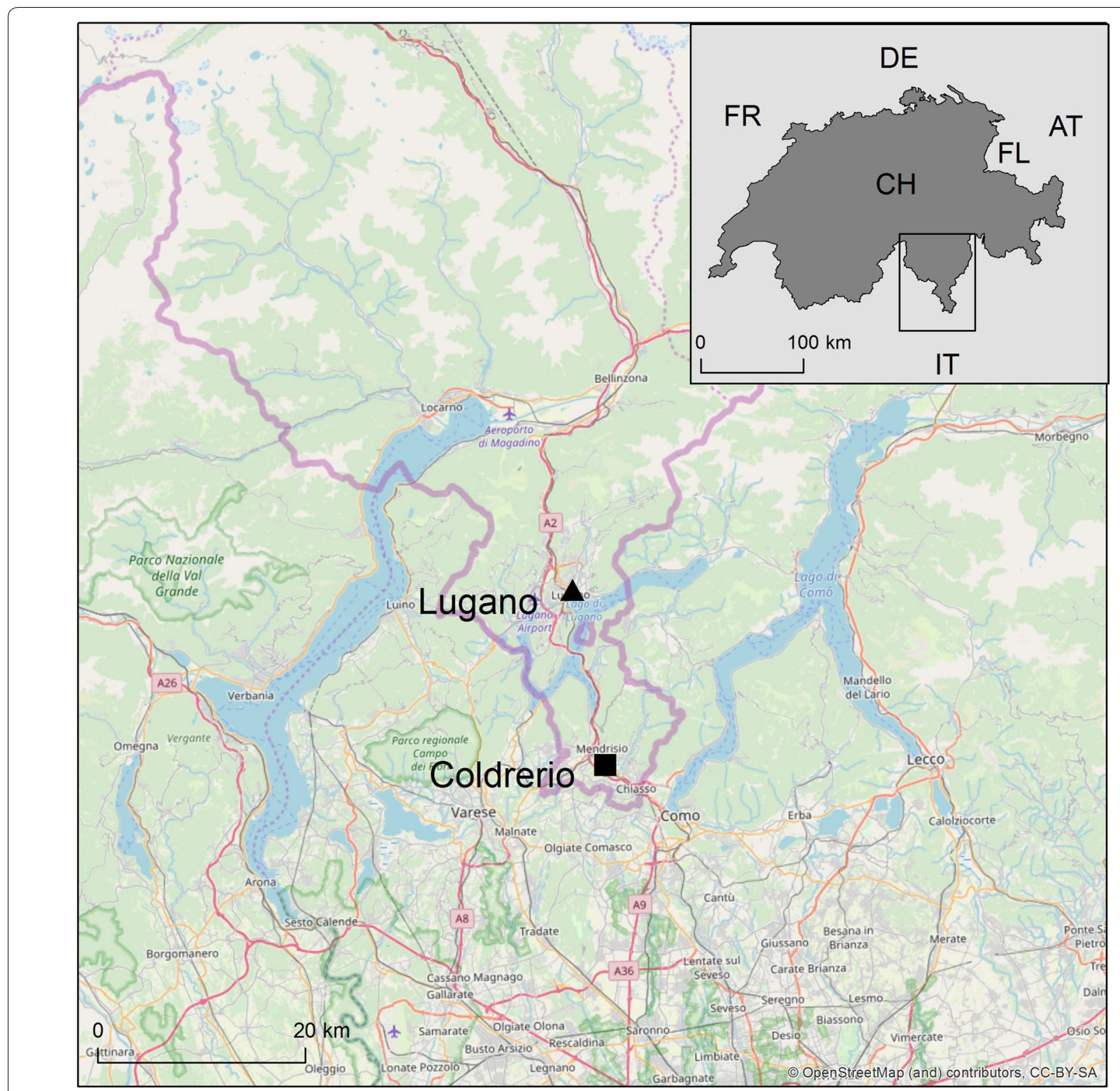

Fig. 1 Study sites of the two MRR experiments in southern Switzerland. Abbreviations: AT, Austria; CH, Switzerland; DE, Germany; FR, France; FL, Lichtenstein; IT, Italy. Map source: OpenStreetMap and contributors CC-BY-SA

kept in place by the rods. Upon emergence from trays placed underneath the unit, the freshly emerged adult mosquitoes have to find their way through the pigmented cloth before they can fly off, picking up fluorescent pigment particles. We attached black fabric to the sides of the aluminium structure with Velcro, closing the unit so that mosquitoes could only exit through the impregnated cloths. In each study site, we deployed two self-marking units and placed them next to each other at the centre of the study area.

\section{Evaluation of the self-marking units under laboratory conditions}

To evaluate the impact on the marking success and potential impact on mosquito survival [29], we conducted preliminary experiments to evaluate the effectiveness of two different dyes of fluorescent pigment, "TP-48: Magenta" and "TP-40: Chartreuse" (RadGlo ${ }^{\circledR}$ TP, Radiant Color N.V., Houthalen, Belgium), and their impact on the survival of field-caught Ae. albopictus. We performed the experiments under controlled laboratory conditions with 


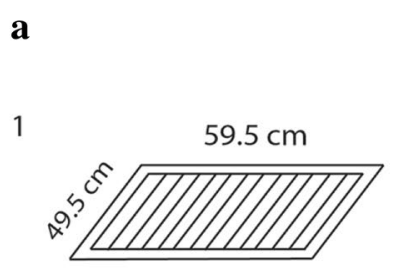

2

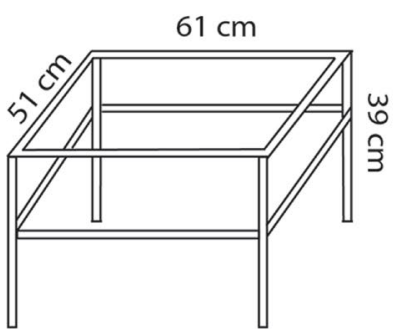

b

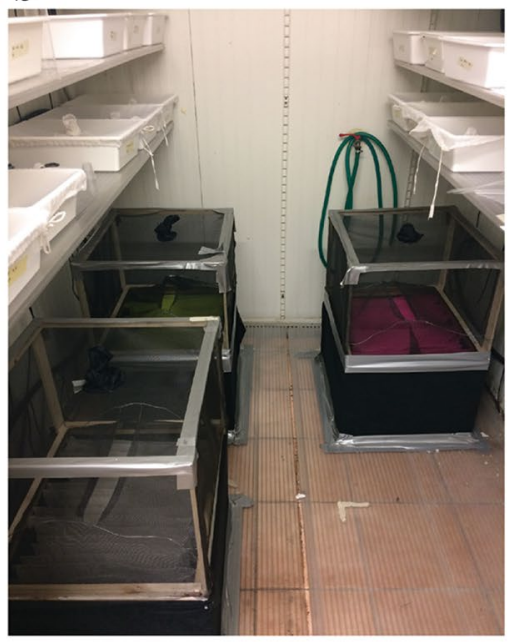

c

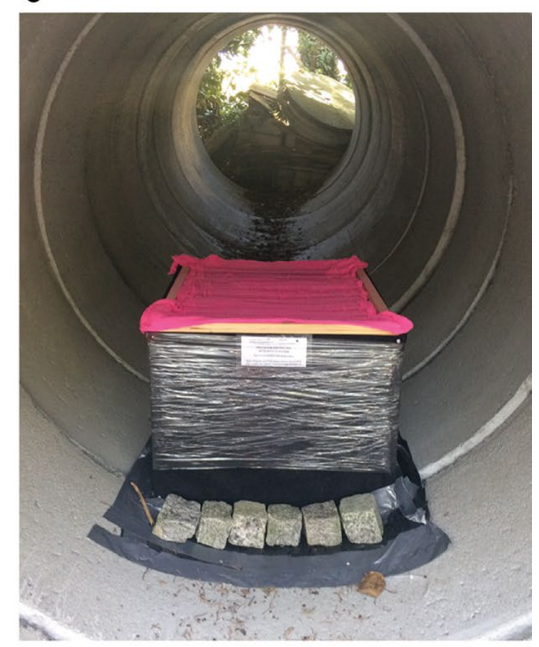

Fig. 2 Mosquito self-marking unit. a The self-marking unit comprises a removable exit grid (1), supporting cheese cloth stripes impregnated with fluorescent pigment, which is mounted on top of a metal structure (2). $\mathbf{b}$ Self-marking units with exit traps mounted on top of the grid with the cheese cloth. A funnel constructed of wire and mesh restricts the mosquitoes to fly only in one direction. c Self-marking unit placed in the field. The plastic foil prevents lizards and other animals from entering the unit

$28 \pm 1{ }^{\circ} \mathrm{C}, 80 \%$ relative humidity and a $14: 10 \mathrm{~h}$ day:night photoperiod. We then compared the performance and impact on mosquito survival of the two fluorescent pigments alongside a negative control (i.e. cheese cloths without pigment). The two colours were chosen, because these have been shown to be the least (TP-48: Magenta) and the most (TP-40: Chartreuse) visible ones for marking Anopheles arabiensis (Adam Saddler, personal observation).

In the experiment, we placed 60 laboratory-reared $A e$. albopictus pupae, that emerged from eggs collected in Parma in 2016 (see [30] for rearing description), in a tray to hatch under each unit. Mosquitoes were left under the units for three consecutive days to give them time to emerge and fly upwards into exit traps we had mounted on top of the marking units to catch the marked mosquitoes (Fig. 2b). From the exit traps we then transferred the adult mosquitoes individually with a mouth aspirator into collection cups covered with a black net (TESA SA manufactures, Renens, Switzerland). Mosquitoes were provided with water only, and on each day we recorded the number of dead mosquitoes. We inspected the dead mosquitoes under a stereo microscope with a UV light (60 LED Purple UV light source for Microscope, Nanyang Srate Optical Instrument Co., Ltd, Nanyang City, China) for the presence or absence of fluorescent pigment. We repeated the experiment three times with different batches of mosquitoes while rotating the positions of the units.

\section{Larval collections}

Across each study area we sampled the mosquitoes as late third- and fourth-instars because these stages allow for morphological identification of Ae. albopictus [31]. The larvae were collected within $3 \mathrm{~km}$ from the marking units, together with the water from their breeding sites, and we transferred them to circular, $13 \mathrm{~cm}$ wide plastic containers containing approx. $350 \mathrm{ml}$ of water and left them to pupate. Initially, the intended area of larval collection was within the $1 \mathrm{~km}$ radius of the study areas, but in order to collect enough larvae we enlarged the search radius to $3 \mathrm{~km}$ away from the marking units. Larvae collected from breeding sites at different time points were kept in separate containers and then placed under the self-marking units once at the pupal stage. For quality control of species identification at the larval stage we put aside a subset of mosquitoes, hatched them out and identified them at the adult stage. We calculated the number of marked mosquitoes by subtracting the number of pupae and adults remaining in the unit from the number of pupae initially placed under the unit on day 0 .

\section{Colour-marking of adults}

We dissolved the fluorescent colour pigment in tap water, soaked strips of cheese cloth in the solution and then let it dry overnight. To avoid cross-contamination we coloured the cheese cloths in a separate laboratory from the one where we screened the mosquitoes for fluorescent pigment particles. In order to investigate the age structure of the local Ae. albopictus population, we used four different colours and swapped between them every 4th day. The colours were chartreuse (TP-40), followed by magenta (TP-48), red (TP-45) and orange (TP-43). That way the marked mosquitoes could be traced back to the 
4-day period in which they emerged from the marking units. We had chosen a time period of four days based on preliminary experiments, leaving enough time for the mosquitoes to emerge from the pupae and fly upwards through the marking unit.

\section{Mosquito recapture}

We recaptured the adult mosquitoes with BG-Sentinel 2 traps (Biogents, Regensburg, Germany) within a radius of $1 \mathrm{~km}$ from the marking units. In order to analyse the distance travelled by the mosquitoes from the marking units, we geo-referenced each trap with a hand-held GPS device (Garmin eTrex 20X, Garmin Ltd, Southampton, UK). An attempt was made to have an even distribution of 16 traps per $\mathrm{km}^{2}$ (i.e. 1 trap within a $250 \mathrm{~m}$ by $250 \mathrm{~m}$ square); however, this was not feasible to implement due to several constraints in the field. Eventually we managed to deploy 28 BG-Sentinels in Coldrerio and 26 in Lugano yielding an overall trap density of 8.9 traps $/ \mathrm{km}^{2}$ and 8.3 traps $/ \mathrm{km}^{2}$, respectively (Fig. 3). All traps, except one in each site, were connected to the main power supply, while the reaming two traps were powered by a battery (NP12-12 Lead-Acid Battery 12 V 12 Ah, Yuasa, Kyoto, Japan). In Coldrerio, the trap closest to the release point was placed $194 \mathrm{~m}$ and the furthest $960 \mathrm{~m}$ from the selfmarking units. In Lugano, the distances were $138 \mathrm{~m}$ and $977 \mathrm{~m}$, respectively. We equipped the BG-Sentinels with BG-Lure cartridges (Biogents) but operated them without $\mathrm{CO}_{2}$. As Ae. albopictus males seek females near the host, they may also be caught with BG-Sentinels [32].

A cause of concern was cross-contamination from marked to unmarked mosquitoes within the same trap, which would lead to unwanted biases in the number of marked mosquitoes. To avoid such cross-contamination, we slightly modified the BG-sentinel traps. The collection bags were wrapped around a cylinder-shaped chicken wire that supported sticky cards (Additional file 1: Figure S1) originally developed for the use in BG-GAT traps (Biogents). The sticky cards immobilised any mosquito inside the bag, preventing the transfer of colour particles from one individual to another. We had previously validated this modification in a laboratory experiment with Ae. aegypti mosquitoes that
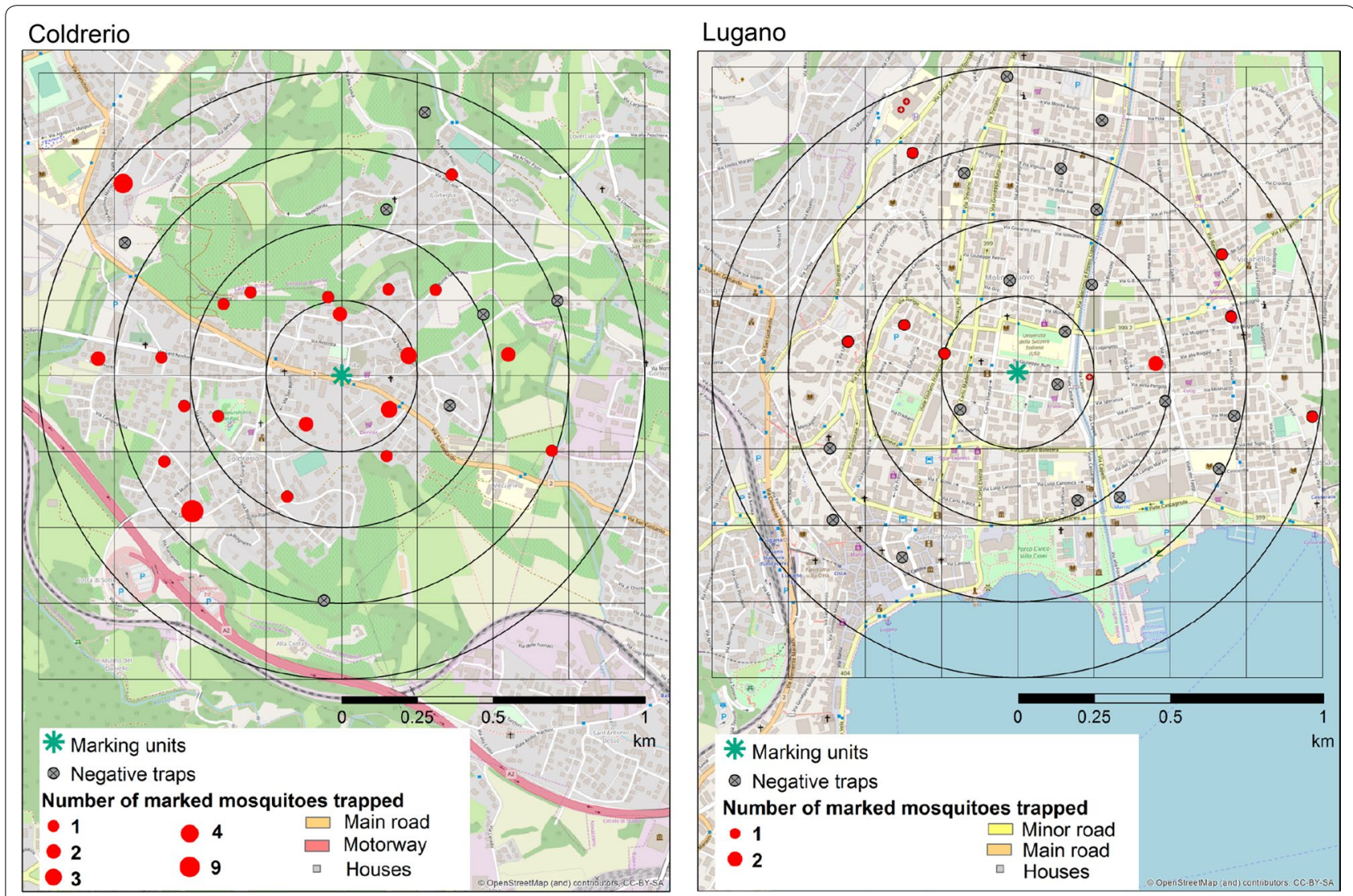

Fig. 3 Map of the MRR set-ups in Coldrerio and Lugano. The traps were deployed in all directions from the self-marking units (green star in the centre) across a circular area with a radius of $1.0 \mathrm{~km}$. Red dots represent positive traps while the size of the dots corresponds to the number of marked mosquitoes caught at each site. Grey dots represent negative traps. Circular black lines represent the four annuli at 250, 500, 750 and 1000 $\mathrm{m}$ from the marking units. Basemap source: OpenStreetMap and contibutors CC-BY-SA 
were released into a $14 \mathrm{~m}^{3}$ free-flight chamber into which we placed such a modified BG-Sentinel trap.

In the field experiments, we replaced the sticky cards from the BG-Sentinels every other day over a period of 22 days from the day the pupae were placed under the marking units and transported the cards inside transparent plastic folders to the laboratory for morphological identification.

\section{Weather parameters}

Weather parameters, including temperature, relative humidity, wind speed and direction, and precipitation were recorded throughout the study. For Coldrerio we obtained the weather data from AgroMeteo [33] from a station located $600 \mathrm{~m}$ from the marking units. In Lugano we deployed a professional weather station (Vantage Pro 2, Davis instruments, Hayward, CA, USA) $2.4 \mathrm{~km}$ away from the marking units near the laboratory. In addition, each BG-Sentinel was equipped with an USB data logger $\left(\mathrm{HOBO}^{\circledR}{ }^{\circledR}\right.$ Pendant ${ }^{\circledR}$ Temperature/Light Data Logger, Onset Computer Corporation, Pocasset, MA, USA) that recorded temperature and light intensity every hour at the top of the trap.

\section{Data analysis}

We analysed the effect of the marking on the survival of mosquitoes using the Kaplan-Meier method that compares survival curves from the unmarked (control) and the marked cohorts by the log-rank test. The dispersal patterns are described by the mean distance travelled (MDT), the maximum distance travelled (MAX) and the flight range (FR) for each locality according to Morris et al. [34]; their formula for MDT includes a correction factor accounting for differences in trap density. For MDT calculation, we divided the circular area into 4 concentric annuli, with a width of $250 \mathrm{~m}$. We calculated the FR on the basis of a linear regression model of the cumulative estimated recapture in the 4 annuli as described in [35]. $\mathrm{FR}_{90}$ represents the maximum flight distance reached by $90 \%$ of all individuals. To estimate the accuracy of the MDT and FR estimation, we calculated a range for the estimates by removing one trap at a time for each location and repeating the calculation for every possible combination. The detection probability was calculated accounting for trapping effort and the area of the annulus [36]. We estimated survival rates with a general nonlinear regression approach as outlined by Buonaccorsi et al. [37] which adjusts for mosquito removal as a result of recapture. Confidence intervals of the survival estimate were calculated by bootstrapping (1000 repeats) using the $n$ lstools package in $\mathrm{R}[38,39]$. For the average life expectancy, we used the formula from Niebylski \& Craig [28]. Population size estimates were calculated using the Lincoln index modified by Bailey. We produced the maps with ArcMap 10.5 (ArcGis 10.0, ESRI Inc., USA) and the graphs with the R package ggplot2 [40]. For the statistical tests we set the level of significance at $\alpha=0.05$.

\section{Results}

\section{Preliminary experiments}

The preliminary laboratory study revealed that the selfmarking units mark between 65\% (magenta) and 89\% (chartreuse yellow) of the emerging Ae. albopictus and that the survival of the marked mosquitoes is statistically not significantly different to the unmarked mosquitoes $\left(\chi^{2}=2, d f=2, P=0.133\right)$, neither for female nor male mosquitoes (female: $X^{2}=4, d f=2, P=0.1$; male: $\chi^{2}=1.6, d f=2, P=0.4$, Additional file 1: Figure S2).

As the marking success did not reach $100 \%$, we changed the size of the cheese cloth strips to one single piece with a total length of $6.3 \mathrm{~m}^{2}$ folded between the rods in order to increase the coloured surface area and, therefore, the marking success. We tested this modification with Ae. aegypti mosquitoes and achieved a minimum marking effectiveness of $82 \%(n=75)$.

\section{Mosquito release and recapture}

We released 521 colour-marked Ae. albopictus in Coldrerio and 519 in Lugano. Taking the marking effectiveness from the preliminary experiments into account, we estimated that 427 mosquitoes have been marked in Coldrerio and 425 in Lugano. While in Coldrerio 40 mosquitoes were recaptured, only 9 mosquitoes were recaptured in Lugano giving an overall recapture rate of $9.3 \%$ and $2.1 \%$, respectively. In Coldrerio we collected a total of $3970 \mathrm{Ae}$. albopictus, 2537 females (64\%) and 1433 males (36\%), and in Lugano a total of 4894, 1994 males (40.7\%) and 2900 females (59.3\%). The detailed results from the mosquito recaptures are reported in Additional file 1: Figure S3 and Table S1.

The distribution of the marked mosquitoes in the two MRR experiments is represented in Fig. 3. In Coldrerio, marked mosquitoes were recaptured in all direction from the marking units (Fig. 3a); $25 \%$ of the traps $(n=28)$ did not catch marked mosquitoes.

\section{Dispersal}

The calculated $\mathrm{FR}_{90}$ is $826(778-849 \mathrm{~m})$ and $861 \mathrm{~m}$ (761$866 \mathrm{~m}$ ) in Coldrerio and Lugano, respectively (average: $843.5 \mathrm{~m}$ ). The calculated MDT is $631 \mathrm{~m}$ in Coldrerio ranging from 576 to $648 \mathrm{~m}$, and $685 \mathrm{~m}$ in Lugano, ranging from 661 to $737 \mathrm{~m}$, respectively. The additional dispersal parameter, such as MAX, is reported in Table 1. To calculate the corrected relative mosquito density, we pooled data from the two sites and found that $93 \%$ of the 
mosquitoes $(n=49)$ were recaptured within $750 \mathrm{~m}$ from the marking units (Fig. 4). No difference was observed between females and males (Fig. 4). The observed pattern does not reflect a typical decay curve in density away from the marking units within our $1 \mathrm{~km}$ radius, and a total of 38 marked mosquitoes $(77.5 \%)$ were recaptured more than $250 \mathrm{~m}$ away from the self-marking units.

Based on the number of mosquitoes recaptured as a function of time following their release, the estimated dispersal rate is between 83 and $333 \mathrm{~m} /$ day (Fig. 5, Additional file 1: Table S1). While we did not find a clear pattern in the results from Lugano, for Coldrerio we observed a distinct relationship between the number of marked mosquitoes captured and the day after their release (Fig. 5). The majority of the mosquitoes were recaptured within the first 7 days after marking and did not fly beyond the $750 \mathrm{~m}$ mark. In contrast, the mosquitoes recaptured between 8 and 11 days were caught in the marking units placed within the two outer annuli.

\section{Survival}

To calculate survival rates, we pooled the data from both study sites. On that basis we estimated that females live on average 8.6 and males 7.8 days (Fig. 6). For the females the average daily survival rate was 0.89 (95\% CI: $0.80-$ $0.94)$, while the daily survival rate for males was 0.88 , (95\% CI: $0.77-0.97$ ) suggesting that $25 \%$ of female $A e$. albopictus reach an age of 12 days, an age of concern for transmission scenarios considering the incubation period of dengue and chikungunya [41], considering the fact that after emergence mosquitoes need a few days until mating and their first blood meal.

\section{Population size}

The population density in Coldrerio was five times lower than in Lugano as estimated with the modified Lincoln index [42]. In Coldrerio the estimated density was 41,953 mosquitoes within the MRR area during the study period, which corresponds to 134 mosquitoes/ha. In contrast, for Lugano the number of mosquitoes was estimated at 208,038 mosquitoes, corresponding to 767 mosquitoes/ ha. The estimates are corrected for the area of the lake overlapping with the $1 \mathrm{~km}$ circle in Lugano. In Coldrerio, we calculated additionally the build area and observed that the estimate would double from 134 mosquitoes/ha to 282 mosquitoes/ha, assuming they are predominantly present in the built environment.

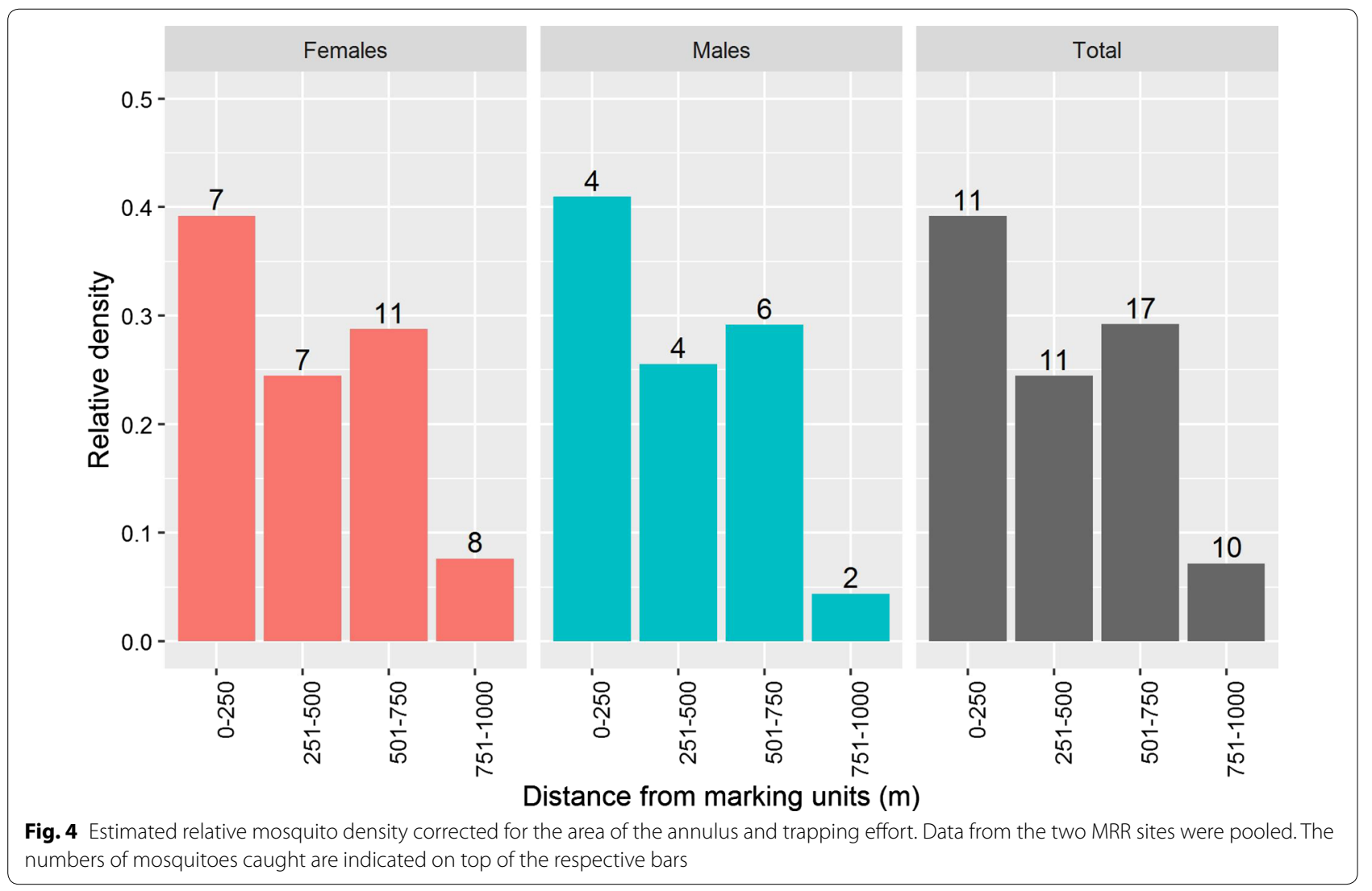




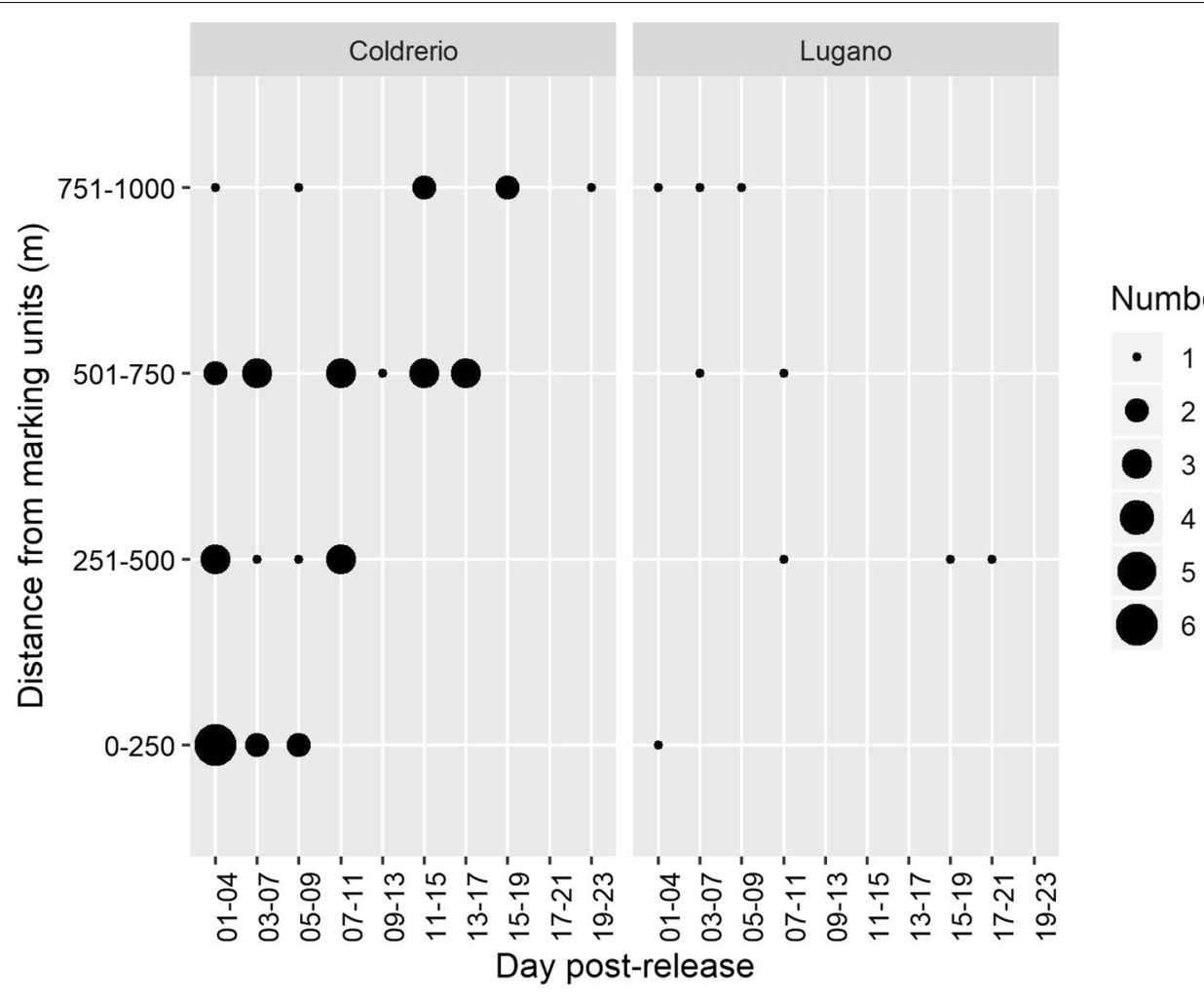

Fig. 5 Number of mosquitoes recaptured as a function of the time following marking. The size of the dots corresponds to the number of marked mosquitoes caught. The number of marked mosquitoes can be traced back to 4-day periods as the different pigments were swapped every fourth day. Additionally, the recapture was conducted only every other day. The day post-treatments consists in a window of four days (i.e. 01-04 means from day 1 to day 4 )

\section{Weather parameters}

In Coldrerio, the data loggers on the BG-Sentinels recorded temperatures ranging between $10.5-56{ }^{\circ} \mathrm{C}$, with a mean of $24.9^{\circ} \mathrm{C}$. As already observed by Crepeau et al. [43], exposure of data loggers to sunlight caused different spikes in the temperature recorded, leading to abnormalities in the maximum temperature registered. The data retrieved from AgroMeteo show a medium temperature during the study period of $22.9{ }^{\circ} \mathrm{C}$, with a minimum of $12.8{ }^{\circ} \mathrm{C}$ and a maximum of $32{ }^{\circ} \mathrm{C}$. Relative humidity ranged between $16.8-100 \%$, with a mean of $65.7 \%$. Only 6 days of rain with a total of $80.6 \mathrm{~mm}$ (Additional file 1: Figure S4) were recorded during the study period. The weather station in Coldrerio did neither record wind direction nor wind speed.

In Lugano, the temperature from the data loggers ranged between $10.2-55{ }^{\circ} \mathrm{C}$, with a mean of $22{ }^{\circ} \mathrm{C}$. The data obtained with our weather station showed a mean temperature of $20^{\circ} \mathrm{C}$ with a minimum of $7.9^{\circ} \mathrm{C}$ and a maximum of $30.9^{\circ} \mathrm{C}$. Relative humidity ranged between $19.0-97.0 \%$, with a mean of $73 \%$. Over the whole study period there was less than $30 \mathrm{~mm}$ rain (Additional file 1: Figure S4). The prevailing winds were from the South-East.

\section{Discussion}

Our aim was to measure how far emerging Ae. albopictus fly to seek a host or a mate, how long they survive and what the mosquito density is in an area of intensive mosquito surveillance and control. These parameters are important for the risk assessment of disease transmission and for making informed choices to minimise that risk. We found that $77.5 \%$ of the recaptured Ae. albopictus individuals flew further than $250 \mathrm{~m}$, the limit that is usually deemed sufficient for vector containment. The average age of females and males was 8.6 and 7.8 days in Coldrerio and Lugano, respectively, while the estimated mosquito population densities were 134 mosquitoes/ha in Coldrerio and 767 mosquitoes/ha in Lugano.

The results of the present study confirm that active dispersal of host-seeking female and male Ae. albopictus may be greater than generally assumed. Previous studies have suggested that the maximum flight range is only around 100 to $200 \mathrm{~m}$ [44-46] and concluded Ae. albopictus to have weak flight capacity [47]. This conclusion has become the general notion on which many guidelines for the surveillance of invasive mosquitoes are based, for example it is recommended to 


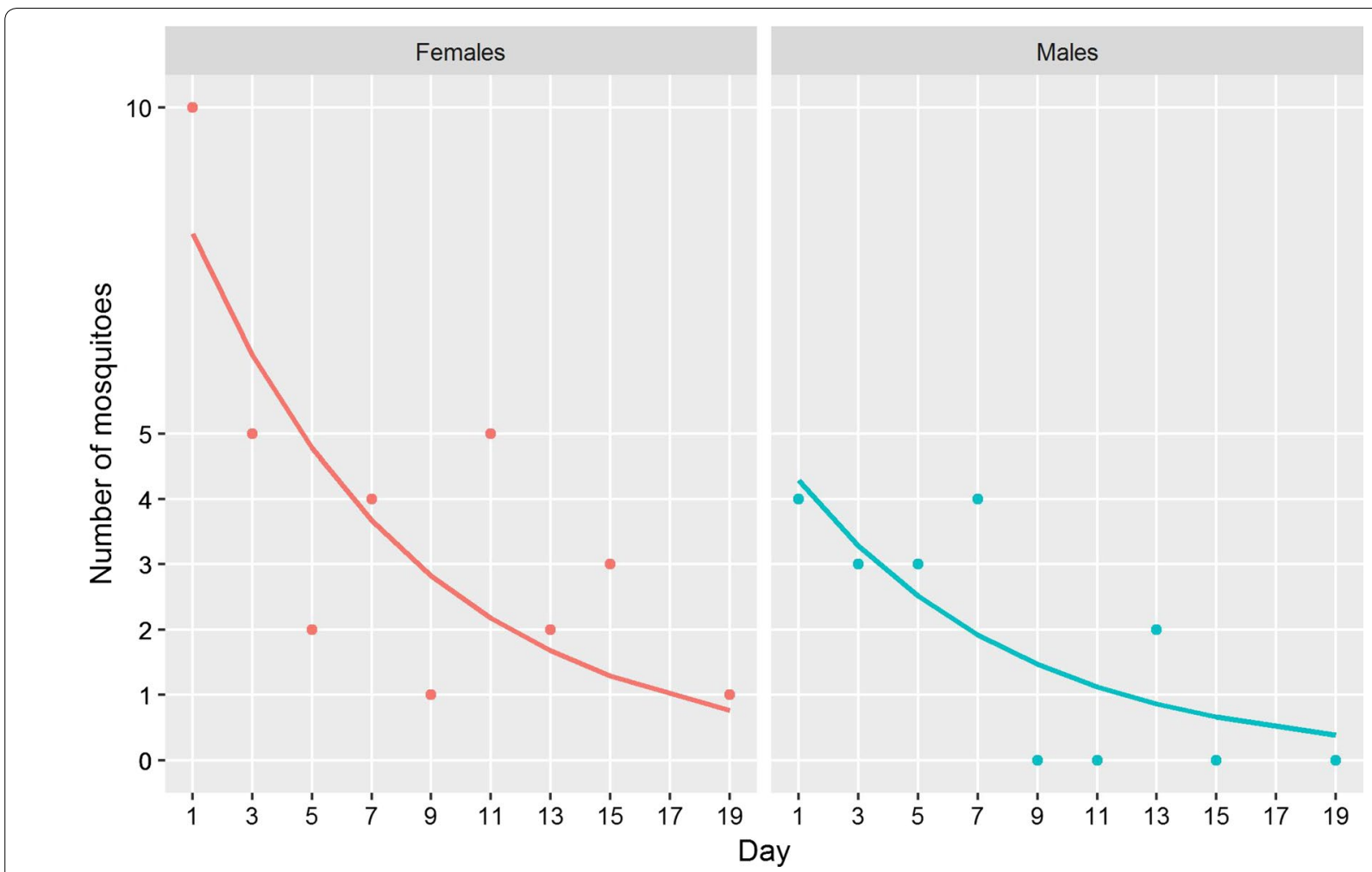

Fig. 6 Daily survival of female and male Ae. albopictus. The points show the total number of mosquitoes caught in the BG-Sentinel traps as a function of age. The line shows the estimated average survival. Data from both study sites were pooled

spray insecticides within a range of 100-300 m around the residence of a viremic person $[18,19]$. In contrast, others have also pointed out that Ae. albopictus females and males may actually fly beyond $1 \mathrm{~km}[36,48]$, and flight performance experiments under laboratory conditions found that well-nourished females even fly as far as $8.6 \mathrm{~km}$ without taking another sugar- or blood meal [15]. These studies, together with the present results, suggest that Ae. albopictus is, indeed, a rather "strong" flyer, and that Ae. albopictus flight distances may not be limited by its flight ability but are rather dependent on other parameters.

The variations observed in the flight range are likely to be an outcome of a mix of environmental factors such as landscape features, availability of hosts, breeding sites and sugar sources [44, 45, 49], but the outcome of an MRR study also depends on a series of factors related to the experimental procedure. For example, while larval growth conditions have been shown to directly influence mosquito dispersal [22], in most MRR studies in Ae. albopictus, the mosquitoes released were sourced from laboratory colonies (Table 1).

In some cases, eggs were field-collected but still reared in the laboratory [50] or in cages placed in the field [45]. Here, we have tried to overcome this drawback by using a set-up that exploits the natural emergence patterns of adults from pupae. Another point of consideration is how the mosquitoes are marked. Ideally the marking method should neither alter the behaviour nor the survival rate of the insects, should be easy to apply, cost-effective and environmentally friendly. Yet, in previous studies, the mosquitoes were frequently removed from a holding cage with a mouth aspirator and then marked individually [51, 52], or in batches, with a pipette releasing a cloud of colour pigment particles $[44,50]$ or by aspirating them into dusted paper cups [45, 49] or cages [46, 48]. While being time-consuming these methods seem far from ideal in many respects.

In order to minimise any bias due to direct handling of mosquitoes, we decided to deploy self-marking units. In addition, this method is cost-effective when compared to other innovative marking methods such as the use of stable isotopes [36], as the construction of the units requires only few materials and the units are simple to build. Additionally, it is difficult to know the number of mosquitoes released when using a stable isotope and there is still a restrictive number of isotopes available that limit the use of this technology. Another advantage of the self-marking unit is that the mosquitoes are steadily released over a longer period of time (i.e. 16 days in the present study), 
mimicking a more natural emergence pattern. In contrast, in previous MRR studies, mosquitoes were released in large numbers from a central point at once, a factor which is likely to have influenced their dispersal pattern as dispersal has been shown to be density-dependent [34, 53].

Another caveat of previous studies is that trap densities tended to be higher closer to the release point, increasing the probability of mosquitoes to be recaptured at closer distances and preventing them from flying further away [36]. Trap position and density may also have a strong influence on the results of MRR studies. Ideally, the traps should be randomly distributed with an equal density across the study area. We, too, intended to have an even trap density, but the numbers of households with a power source to run the trap were limited. In some studies [50, 54], the maximum distance flown corresponds to mosquitoes captured at the outer edge of the trapping area. Guerra et al. [55] have also noted that study areas are frequently too small to report maximum flight ranges. To some extent this is also a limitation of the present study as we have still recaptured mosquitoes in the outermost traps. However, we may argue that the relative densities were substantially lower in the outer annulus, as compared to the inner annuli, suggesting that we were able to cover most of the potential flight range. The recapture rate in Coldrerio is in line with previous studies, where the corrected chance to recapture a marked mosquito was 9.3\% while the recapture rate was relatively low in Lugano (2.1\%). The contradicting results may be explained, among other factors, by differences in the landscape of the two study sites and the number of traps competing with human hosts. Coldrerio is located in a rural area with a lower human population density, has lower buildings and a road system that is more open. Together, these factors might have contributed to an increased recapture rate in Coldrerio as compared to Lugano.

According to the Lincoln formula, the estimated mosquito densities in the two study sites were 134 and 767 mosquitoes/ha in Coldrerio and in Lugano, respectively. The Lincoln estimate may be an overestimation of the true population size [45], especially in Lugano where the chance to capture a mosquito may be considered lower due to the landscape of the city environment. Yet, the figure is still informative as a comparative index. When comparing our results to similar estimates from other MRR studies in Europe $[45,56]$, where densities were between 50-236 adult mosquitoes/ha, our results suggest rather high population densities.

Female survival is a highly informative parameter for the risk assessment of disease transmission in a given area [57]. The daily survival rates calculated in this study are comparable with results previously reported $[28,44$, $46,50]$. As observed in the present study, male survival rates have previously also been reported to be lower than for females [28], although the differences in the present study was rather small. The oldest mosquito recaptured in our study was a female with an age between 19-23 days after release, $805 \mathrm{~m}$ away from the marking units. In a laboratory infection study, Heitmann et al. [58] found that European Ae. albopictus show high transmission rates for chikungunya at temperatures of $18{ }^{\circ} \mathrm{C}$. For both sites in our study more than 14 consecutive days had an average temperature of $18{ }^{\circ} \mathrm{C}$ or above (Additional file 1: Figure S4), suggesting that conditions in Ticino seem favourable for a chikungunya transmission during the summer months, even more so as extrinsic incubation period of chikungunya virus in Ae. albopictus is only a few days $[41,59]$.

\section{Conclusions}

Self-marking units are an effective tool to mark mosquitoes with the main advantage of using wild individuals and a simple marking process that does not impact mosquito survival. We, therefore, recommend the use of the self-marking units for future MRR studies. Using this approach, we found that mosquitoes survive long enough to potentially transmit arboviral disease in our study area. Our results also suggest that host-seeking Ae. albopictus females may travel further than previously assumed for European mosquito populations. This finding has direct implications for vector control as emergency treatments around positive cases, as well as surveillance and control around detections of new infestations, might need to be extended beyond the usual recommended range of just a few hundred metres. The extensive survival rates, together with the long distances travelled, underlines the importance of dealing with this highly invasive vector in a coordinated manner across municipalities and country boundaries.

\section{Supplementary information}

Supplementary information accompanies this paper at https://doi. org/10.1186/s13071-019-3837-5.

Additional file 1: Figure S1. Modification of the BG-Sentinel trap. A cylinder-shaped chicken wire $(34 \times 10 \mathrm{~cm})$ supports the two sticky cards inserted into the BG-Sentinel catch bag to avoid colour cross-contamination between mosquitoes. Figure $\mathbf{S 2}$. Performance of self-marking units with wild Ae. albopictus. Two colours, pink and yellow, were examined for their marking success and their impact on mosquito survival, and compared to a negative control (i.e. cheese cloth without fluorescent dust). a Marking success with the two different colours. While the marking success for yellow was very high, the success rate for pink was lower. b The survival of Ae. albopictus did not differ, neither between colours nor between a colour and the negative control $\left(x^{2}=2, d f=2, P=0.133\right)$. The reported male to female ratio is $1: 6$ and the survival of male and female Ae. albopictus did not differ (female $X^{2}=4, d f=2, P=0.1$, male $X^{2}=1.6, d f=2, P=0.4$ ). Figure S3. Total number of mosquito collected over the study period. The numbers on top of the bar represents the number of marked mosquitoes. Figure S4. Variation of daily mean temperature, mean relative humidity 
and precipitation during the study period in the two study sites. The blue bars show the daily precipitation in $\mathrm{mm}$ per day. Table S1. Number of recaptured Ae. albopictus during the two MRR studies in the annuli used for MDT calculation.

\section{Abbreviations}

BG: Biogents; FR: flight range; MDT: mean distance travelled; MAX: maximum distance travelled; MRR: mark-release-recapture

\section{Acknowledgements}

The authors are very thankful to Eleonora Flacio and the Gruppo Lavoro Zanzare for hosting us in their laboratory during the field work. We would like to thank Arianna Puggioli and Romeo Bellini from the Centro Agricoltura Ambiente G. Nicoli, Italy, for their support during the laboratory experiment. Many thanks to Sarah Moore for her inputs on the marking units. A great thank goes to Annika Materna for her help and support during the field work. Many thanks to Marco Marazzi and Michele Conconi, and their team, from the community of Coldrerio and Claudio Schraemmli from the community of Lugano for supporting us in identifying suitable trap sites. A special thanks goes to Fabien Haas and Kilian Schwarzen for their help in building the marking units and the exit traps. We are very grateful to the members of the Vector Control Group for their continuous support. Finally, we would like to thank all citizens from Coldrerio and Lugano that granted access to their properties to place the mosquito traps.

\section{Authors' contributions}

LV, AS and PM conceived and designed the study. LV performed the field work. LV, AS and PM analysed the data and interpreted the results. LV drafted the manuscript and AS and PM revised it. All authors read and approved the final manuscript.

\section{Funding}

The research leading to these results received funding from the Swiss Confederation and the Cantons of Aargau, Basel-Landschaft and Basel-Stadt within EU-Programme INTERREG Upper Rhine under the project number 11.7 TIGER. The BG-Sentinel traps were kindly sponsored by Verfora SA, Switzerland. Funding for the preliminary laboratory studies has been received from the Stiftung Emilia Guggenheim-Schnurr der Naturforschenden Gesellschaft in Basel and the Basel Foundation for Experimental Zoology. Adam Saddler acknowledges support from the Swiss National Science Foundation, grant number 320030_163473.

\section{Availability of data and materials}

The datasets supporting the conclusions of this article are included within the article and Additional file 1.

\section{Ethics approval and consent to participate}

The study has been submitted to the local ethics committee and it did not require formal approval, while it follows the general ethical principles for research in humans (EKNZ Req-2017-00471).

\section{Consent for publication}

Not applicable.

\section{Competing interests}

The authors declare that they have no competing interests.

\section{Author details}

${ }^{1}$ Swiss Tropical and Public Health Institute, Socinstrasse 57, P.O. Box, 4002 Basel, Switzerland. ${ }^{2}$ University of Basel, Petersplatz 1, P.O. Box, 4001 Basel, Switzerland. ${ }^{3}$ Ifakara Health Institute, Environmental Health and Ecological Sciences, P.O. Box 74, Bagamoyo, Tanzania.

Received: 5 July 2019 Accepted: 3 December 2019 Published online: 12 December 2019
References

1. IUCN/SSC. Invasive Species Specialist Group (ISSG). http://www.issg.org/ publications.htm\#worst100. Accessed 13 Nov 2018.

2. Gratz NG. Critical review of the vector status of Aedes albopictus. Med Vet Entomol. 2004:18:215-27.

3. Paupy C, Delatte H, Bagny L, Corbel V, Fontenille D. Aedes albopictus, an arbovirus vector: from the darkness to the light. Microbes Infect. 2009; 11:1177-85

4. Rezza G, Nicoletti L, Angelini R, Romi R, Finarelli A, Panning M, et al. Infection with chikungunya virus in Italy: an outbreak in a temperate region. Lancet. 2007;370:1840-6.

5. Venturi G, Luca MD, Fortuna C, Remoli ME, Riccardo F, Severini F, et al. Detection of a chikungunya outbreak in central Italy, August to September 2017. Euro Surveill. 2017:22:17-00646.

6. Gjenero-Margan I, Aleraj B, Krajcar D, Lesnikar V, Klobučar A, Pem-Novosel I, et al. Autochthonous dengue fever in Croatia, August-September 2010. Euro Surveill. 2011;16:19805

7. Grandadam M, Caro V, Plumet S, Thiberge JM, Souarès Y, Failloux $A B$, et al. Chikungunya virus, southeastern France. Emerg Infect Dis. 2011;17(5):910-3.

8. Marchand E, Prat C, Jeannin C, Lafont E, Bergmann T, Flusin O, et al. Autochthonous case of dengue in France, October 2013. Euro Surveill. 2013;18:20661.

9. Delisle E, Rousseau C, Broche B, Leparc-Goffart I, L'Ambert G, Cochet A, et al. Chikungunya outbreak in Montpellier, France, September to October 2014. Euro Surveill. 2015;20:21108.

10. Aranda C, Martínez MJ, Montalvo T, Eritja R, Navero-Castillejos J, Herreros E, et al. Arbovirus surveillance: first dengue virus detection in local Aedes albopictus mosquitoes in Europe, Catalonia, Spain, 2015. Euro Surveill. 2018;23:1700837.

11. Calba C, Guerbois-Galla M, Franke F, Jeannin C, Auzet-Caillaud M, Grard $\mathrm{G}$, et al. Preliminary report of an autochthonous chikungunya outbreak in France, July to September 2017. Euro Surveill. 2017:22:17-00647.

12. Moore CG, Mitchell CJ. Aedes albopictus in the United States: ten-year presence and public health implications. Emerg Infect Dis. 1997;3:329-34.

13. Flacio E, Engeler L, Tonolla M, Lüthy P, Patocchi N. Strategies of a thirteen year surveillance programme on Aedes albopictus (Stegomyia albopicta) in southern Switzerland. Parasites Vectors. 2015;8:208.

14. Eritja R, Palmer JRB, Roiz D, Sanpera-Calbet I, Bartumeus F. Direct evidence of adult Aedes albopictus dispersal by car. Sci Rep. 2017:7:14399.

15. Kaufmann C, Collins LF, Brown MR. Influence of age and nutritional status on flight performance of the Asian tiger mosquito Aedes albopictus (Diptera: Culicidae). Insects. 2013;4:404-12.

16. WHO. Dengue: guidelines for diagnosis, treatment, prevention, and control. Geneva: World Health Organization; 2009. p. 147.

17. DGS. Instruction no DGS/RI1/2015/125 du 16 avril 2015 mettant à jour le guide relatif aux modalités de mise en oeuvre du plan anti-dissémination du Chikungunya et de la Dengue en métropole, 2015. https://solidarite s-sante.gouv.fr/IMG/pdf/Instruction_et_Guide_chik_dengue_16_avril 2015.pdf. Accessed 13 June 2019

18. Servizio sanitario regionale Emilia-Romagna. Zanzara tigre e altri insetti pericoli pubblici: line guida per gli operatori dell'Emilia-Romagna. Emilia Romagna: Servizio sanitario regionale Emilia-Romagna, 2016. Accessed 13 Jun 2019.

19. LIFE CONOPS. Management plan for Aedes albopictus in Greece and Italy. http://www.conops.gr/management-plan-for-aedes-albopictus-in-greec e?lang=en. Accessed 13 Jun 2019.

20. Hagler JR, Jackson CG. Methods for marking insects: current techniques and future prospects. Annu Rev Entomol. 2001;46:511-43.

21. Silver JB. Mosquito ecology: field sampling methods. New York: Springer Science and Business Media; 2007

22. Mori A. Effects of larval density and nutrition on some attributes of immature and adult Aedes albopictus. Trop Med. 1979;21:85-103.

23. Flacio E, Lüthy P, Patocchi N, Guidotti F, Tonolla M, Peduzzi R. Primo ritrovamento di Aedes albopictus in Svizzera. Boll Della Soc Ticinese Sci Nat. 2004;92:141-2. 
24. Suter TT, Flacio E, Fariña BF, Engeler L, Tonolla M, Regis LN, et al. Surveillance and control of Aedes albopictus in the Swiss-Italian border region: differences in egg densities between intervention and non-intervention areas. PLoS Negl Trop Dis. 2016;10:e0004315.

25. Flacio E, Engeler L, Tonolla M, Müller P. Spread and establishment of Aedes albopictus in southern Switzerland between 2003 and 2014: an analysis of oviposition data and weather conditions. Parasites Vectors. 2016;9:304.

26. Bilanz der ständigen Wohnbevölkerung nach Jahr, Kanton, Bezirk, Gemeinde, Staatsangehörigkeit (Kategorie), Geschlecht und Demographische Komponente. http://www.pxweb.bfs.admin.ch/pxweb/de/px-x0102020000_201/-/px-x-0102020000_201.px/. Accessed 24 Jan 2019.

27. Niebylski ML, Meek CL. A self-marking device for emergent adult mosquitoes. J Am Mosq Control Assoc. 1989;5:86-90.

28. Niebylski ML, Craig GB. Dispersal and survival of Aedes albopictus at a scrap tire yard in Missouri. J Am Mosq Control Assoc. 1994;10:339-43.

29. Dickens BL, Brant HL. Effects of marking methods and fluorescent dusts on Aedes aegypti survival. Parasites Vectors. 2014;7:65

30. Mastrantonio V, Crasta G, Puggioli A, Bellini R, Urbanelli S, Porretta D. Cannibalism in temporary waters: simulations and laboratory experiments revealed the role of spatial shape in the mosquito Aedes albopictus. PLoS ONE. 2018;29:13.

31. Farajollahi Ary, Price Dana C. A rapid identification guide for larvae of the most common North American container-inhabiting Aedes species of medical importance. J Am Mosq Control Assoc. 2013;29:203-22.

32. Farajollahi A, Kesavaraju B, Price DC, Williams GM, Healy SP, Gaugler R, Nelder MP. Field efficacy of BG-Sentinel and industry-standard traps for Aedes albopictus (Diptera: Culicidae) and West Nile virus surveillance. J Med Entomol. 2009;46:919-25.

33. Agrometeo. http://www.agrometeo.ch/it/meteorology/datas. Accessed 21 Jan 2019.

34. Morris CD, Larson V, Lounibos L. Measuring mosquito dispersal for control programs. J Am Mosq Control Assoc. 1991;7:608-15.

35. White DJ, Morris C. Bionomics of anthropophilic Simuliidae (Diptera) from the Adirondack mountains of New York State, USA. J Med Entomol. 1985:22:190-9.

36. Medeiros $\mathrm{MCl}$, Boothe EC, Roark EB, Hamer GL. Dispersal of male and female Culex quinquefasciatus and Aedes albopictus mosquitoes using stable isotope enrichment. PLoS Negl Trop Dis. 2017;11:e0005347.

37. Buonaccorsi JP, Harrington LC, Edman JD. Estimation and comparison of mosquito survival rates with release-recapture-removal data. J Med Entomol. 2003;40:6-17.

38. Baty F, Ritz C, Charles S, Brutsche M, Flandrois JP, Delignette-Muller ML. A Toolbox for nonlinear regression in R: the package nlstools. J Stat Softw. 2015;66:1-21.

39. R Core Team. R: a language and environment for statistical computing. Vienna: R Foundation for Statistical Computing; 2019. http://www.R-proje ct.org/. Accessed 21 Jan 2019.

40. Wickham H. ggplot2: elegant graphics for data analysis. New York: Springer Science and Business Media; 2009.

41. Moloney RM, Kmush B, Rudolph KE, Cummings DAT, Lessler J. Incubation periods of mosquito-borne viral infections: a systematic review. Am J Trop Med Hyg. 2014;90:882-91.

42. Gaskell TJ, George BJ. A Bayesian modification of the Lincoln index. J Appl Ecol. 1972;9:377.

43. Crepeau TN, Healy SP, Bartlett-Healy K, Unlu I, Farajollahi A, Fonseca DM. Effects of Biogents Sentinel trap field placement on capture rates of adult Asian tiger mosquitoes, Aedes albopictus. PLoS ONE. 2013;8:e60524.

44. Bellini R, Albieri A, Balestrino F, Carrieri M, Porretta D, Urbanelli S, et al. Dispersal and survival of Aedes albopictus (Diptera: Culicidae) males in Italian urban areas and significance for sterile insect technique application. J Med Entomol. 2010;47:1082-91.

45. Marini F, Caputo B, Pombi M, Tarsitani G, Della Torre A. Study of Aedes albopictus dispersal in Rome, Italy, using sticky traps in mark-releaserecapture experiments. Med Vet Entomol. 2010;24:361-8.

46. Lacroix R, Delatte H, Hue T, Reiter P. Dispersal and survival of male and female Aedes albopictus (Diptera: Culicidae) on Réunion Island. J Med Entomol. 2009;46:1117-24.
47. Verdonschot PFM, Besse-Lototskaya AA. Flight distance of mosquitoes (Culicidae): a metadata analysis to support the management of barrier zones around rewetted and newly constructed wetlands. Limnologica. 2014;45:69-79.

48. Maciel-de-Freitas R, Neto RB, Gonçalves JM, Codeço CT, Lourenço-deOliveira R. Movement of dengue vectors between the human modified environment and an urban forest in Rio de Janeiro. J Med Entomol. 2006;43:1112-20

49. Gouagna LC, Dehecq J-S, Fontenille D, Dumont Y, Boyer S. Seasonal variation in size estimates of Aedes albopictus population based on standard mark-release-recapture experiments in an urban area on Reunion Island. Acta Trop. 2015;143:89-96.

50. Le Goff G, Damiens D, Ruttee AH, Payet L, Lebon C, Dehecq JS, Gouagna LC. Field evaluation of seasonal trends in relative population sizes and dispersal pattern of Aedes albopictus males in support of the design of a sterile male release strategy. Parasites Vectors. 2019:12:81.

51. Takagi M, Tsuda Y, Suzuki A, Wada Y. Movement of individually marked Aedes albopictus females in Nagasaki, Japan. Trop Med. 1995:37:79-85.

52. Tsuda Y, Kamezaki H. Mark-release-recapture study on movement of mosquitoes: individual marking method and short-term study of Aedes albopictus and Armigeres subalbatus in residential area on Ishigaki island, Japan. Med Entomol Zool. 2013;65:61-6.

53. Service MW. Mosquito (Diptera: Culicidae) dispersal - the long and short of it. J Med Entomol. 1997;34:579-88.

54. Davis TJ, Kaufman PE, Tatem AJ, Hogsette JA, Kline DL. Development and evaluation of an attractive self-marking ovitrap to measure dispersal and determine skip oviposition in Aedes albopictus (Diptera: Culicidae) field populations. J Med Entomol. 2016;53:31-8.

55. Guerra CA, Reiner RC, Perkins TA, Lindsay SW, Midega JT, Brady OJ, et al. A global assembly of adult female mosquito mark-release-recapture data to inform the control of mosquito-borne pathogens. Parasites Vectors. 2014;7:276.

56. Carrieri M, Angelini P, Venturelli C, Maccagnani B, Bellini R. Aedes albopictus (Diptera: Culicidae) Population size survey in the 2007 chikungunya outbreak area in Italy. II: estimating epidemic thresholds. J Med Entomol. 2012:49:388-99.

57. ECDC. European Centre for Disease Prevention and Control. Guidelines for the surveillance of invasive mosquitoes in Europe. Stockholm: European Centre for Disease Prevention and Control; 2012. https://www. ecdc.europa.eu/sites/portal/files/media/en/publications/Publications/ TER-Mosquito-surveillance-guidelines.pdf. Accessed 13 June 2019.

58. Heitmann A, Jansen S, Lühken R, Helms M, Pluskota B, Becker N, et al. Experimental risk assessment for chikungunya virus transmission based on vector competence, distribution and temperature suitability in Europe, 2018. Euro Surveill. 2018;23:1800033.

59. Dubrulle M, Mousson L, Moutailler S, Vazeille M, Failloux AB. Chikungunya virus and Aedes mosquitoes: saliva is infectious as soon as two days after oral infection. PLOS ONE. 2009;4:5895.

60. Worcester DJ, Bonnet DD. The dispersal of Aedes albopictus in the territory of Hawaii. Am J Trop Med Hyg. 1946;26:465-76.

61. Honório NA, Silva WDC, Leite PJ, Gonçalves JM, Lounibos LP, Lourençode-Oliveira R. Dispersal of Aedes aegypti and Aedes albopictus (Diptera: Culicidae) in an urban endemic dengue area in the State of Rio de Janeiro, Brazil. Mem Inst Oswaldo Cruz. 2003;98:191-8.

62. Liew C, Curtis CF. Horizontal and vertical dispersal of dengue vector mosquitoes, Aedes aegypti and Aedes albopictus, in Singapore. Med Vet Entomol. 2004;18:351-60.

63. Rosen L, Rozeboom LE, Reeves WC, Saugrain J, Gubler DJ. A field trial of competitive displacement of Aedes polynesiensis by Aedes albopictus on a Pacific atoll. Am J Trop Med Hyg. 1976;25:906-13.

\section{Publisher's Note}

Springer Nature remains neutral with regard to jurisdictional claims in published maps and institutional affiliations. 